\title{
A QUÍMICA É SEMPRE BOA
}

Nas últimas semanas, alguns temas relacionados com a Química têm sido bastante debatidos nos meios de comunicação. Nem sempre as opiniões expressas nas matérias são favoráveis e, na maioria das vezes, as críticas são injustas. Já há muito tempo a imagem da Química vem sendo desgastada, devido às associações com desastres ecológicos e também pelo excesso de uso da palavra química como um verbete popular. Essa palavra tornou-se sinômino de algo nocivo - por exemplo, quando alguém diz que este ou aquele produto tem "química", já está embutida a conotação de ruim. Só popularmente na química do amor é que a conotação é positiva, quando alguém diz que há uma química entre duas pessoas. Neste caso, não hove necessidade de dizer uma "química boa", pois na terminologia do amor a química é sempre boa. Para provar este ponto, basta-nos citar um trecho de Gabriel Garcia Marques: "Tenho uma química ruim com os animais, do mesmo jeito que com as crianças assim que começam a falar"" onde o autor adjetivou de ruim a química para expressar seu sentimento.

Retornando aos temas relacionados com a Química que têm agitado os meios de comunicação, destacamos alguns mais relevantes. O primeiro selecionado é o mais antigo (2000): o desastre ecológico no Rio Pomba (MG), causado por uma fábrica de papel que deixou vazar resíduos tóxicos, oriundos de processo antiquado, causando grande comoção nacional pelos danos à população. Entre as substâncias tóxicas despejadas estava a dioxina, que demora de 10 a 20 anos para manifestar seus efeitos no organismo humano. O segundo, bem mais recente (2007), foi causado pela Mineradora Rio Pomba Cataguases que mantinha uma barragem, pobremente conservada em local inapropriado, de resíduos de bauxita. A lama estava represada em uma barragem próxima ao Rio Pomba, que ao se romper invadiu diversas cidades e chegou a outros rios da região atingindo, inclusive, outros estados. Deve-se ressaltar que esta mineradora não é uma indústria química. $\mathrm{O}$ terceiro, de 2002, foi o maior desastre fluvial do país, com vazamento de 4 milhões de litros de petróleo cru da Refinaria Getúlio Vargas em Araucária, Paraná, para o meio ambiente. Esse acidente superou o vazamento ocorrido no início do ano na Baía de Guanabara, que foi contaminada com 1,3 milhões de litros de óleo combustível. Uma sucessão de erros humanos e equipamentos em manutenção, com sistemas obsoletos de vigilância e monitoração, aliados à negligência, permitiram esse vazamento, sem qualquer controle. E o quarto tema, considerado o mais grave e complexo são as catástrofes climáticas e as mudanças que estão ocorrendo em nível mundial. Nunca se viu mudanças tão rápidas e com efeitos tão devastadores como têm ocorrido nos últimos anos: lugares do planeta normalmente frios têm sido castigados por ondas de calor de até $40{ }^{\circ} \mathrm{C}$; ciclones atingem o Brasil; há aumento no número de desertos e de regiões desertificadas; fortes furacões causam mortes e as calotas polares estão derretendo. Pesquisadores já haviam alertado há várias décadas que o planeta sentiria no futuro o impacto do descuido do homem com o ambiente, pois sabiam que alguns gases, como $\mathrm{CO}_{2}$, ozônio e CFC's, ocasionariam o efeito estufa ao absorverem a radiação infravermelha emitida pela superfície da Terra e irradiariam, por sua vez, alguma da energia absorvida de volta para a superfície. Diversos modelos foram desenvolvidos para este fim, demonstrando o impacto causado. Por exemplo, o mecanismo de depleção da camada de ozônio rendeu um prêmio Nobel de Química para Paul Crutzen, Mario Molina e F. Sherwood Rowland pelos trabalhos em Química Atmosférica, especialmente no que se refe- re à formação e decomposição da camada de ozônio. Não obstante, o acordo internacional para redução da emissão dos gases poluentes que aumentam o efeito estufa no planeta não foi assinado por todos os países. Novamente, o lucro falou mais alto; a ganância sobrepujou a racionalidade. Agora culpam a ciência, argumentando que os cientistas não sabem como reverter esses trágicos sintomas. Evidentemente é muito mais difícil reverter este processo do que teria sido evitá-lo.

Todos os exemplos apresentados tiveram origem devido à negligência, falha, ou ausência dos governos, falta de visão, lucratividade, impunidade etc...

$\mathrm{O}$ aquecimento global é o problema mais grave que a humanidade precisa enfrentar, pois sua origem é diversificada, sua solução é complexa e seus efeitos são mundiais. A análise dessa situação nos leva diretamente a reflexões sobre políticas de ciência e tecnologia nacionais, bem como sobre o papel dos pesquisadores neste contexto. Há algum tempo a área da Química vem trabalhando com a concepção de uma química ambientalmente mais recomendada, que alguns gostam de chamar de Química Verde. Porém, muitas outras ações concomitantes precisam ser tomadas (educação ambiental, substituição de processos e produtos químicos, tratamento de resíduos ${ }^{2}$, novos materiais poliméricos, uso de $\mathrm{CO}_{2}$ como matéria-prima em novos processos, reflorestamento etc.). Porém, a principal é substituir os combustíveis fósseis (recursos não renováveis) e utilizar novas fontes energéticas. O Brasil tem dado o exemplo de uso em larga escala de novas fontes energéticas renováveis com seu programa de álcool e, mais recentemente, com a introdução do biodiesel, combustível preparado a partir de ácidos graxos e seus derivados, mas tem contribuído para o aquecimento global com o desmatamento das florestas brasileiras. Estas sim, são as nossas maiores riquezas. O que resta das nossas florestas conserva uma biodiversidade de microorganismos e espécies que precisam ser estudadas pelos nossos cientistas, por exemplo, em busca de novos fitofármacos.

A SBQ vem discutindo com a comunidade diversos temas considerados importantes para os caminhos da Química no país. Em 2002 foi debatido, em Salvador na 25 RASBQ, o tema "A Química no Brasil: Situação Atual e Perspectivas", dando origem a um documento importante sobre os eixos mobilizadores da Química ${ }^{3}$. Já neste documento levantava-se a necessidade da inclusão deste tema nos currículos dos cursos de Química no Brasil, para que o país crie uma massa crítica competente e capaz de lidar com os problemas que surgirão.

A Química é sempre boa quando utilizada com responsabilidade e sempre será ruim quando utilizada por empresários gananciosos e ávidos por altas margens de lucro.

\section{Vitor F. Ferreira} Editor de $Q N$

\section{REFERÊNCIAS}

1. Marques, G. G.; Memórias de Minhas Putas Tristes, Ed. Record, 2005.

2. Gerbase, A. E.; Coelho, F. S.; Machado, P. F. L.; Ferreira, V. F.; Quim. Nova 2005, 28,3 .

3. de Andrade, J. B.; Cadore, S.; Vieira, P. C.; Zucco, C.; Pinto, A. C.; Quim. Nova 2003, 26, 445 . 
Química Nova publica artigos com resultados originais de pesquisa, trabalhos de revisão, divulgação de novos métodos ou técnicas, educação e assuntos gerais, em português, inglês e espanhol. Os artigos submetidos à revista são avaliados por consultores $a d$ hoc (do Brasil e do exterior) especialistas na área envolvida e que, eventualmente, podem pertencer ao Conselho Editorial. A edição de Química Nova está a cargo de um corpo editorial e suas linhas gerais e planejamento de longo prazo estão sob responsabilidade dos Editores e do Conselho Editorial.

A versão on line está disponível em:

http://quimicanova.sbq.org.br/quimicanova.htm

Química Nova é uma publicação bimestral, distribuída gratuitamente a todos os sócios ativos da SBQ.

Indexação: Chemical Abstracts, ISI e SciELO.

\section{Editores}

Susana I. Córdoba de Torresi (USP)

Vera L. Pardini (USP)

Vitor F. Ferreira (UFF)

\section{Gerente Editorial}

Pricila E. A. Gil

\section{Conselho Editorial}

Adriana V. Rossi (UNICAMP)

Aldo J. G. Zarbin (UFPR)

Ana Maria Rocco (UFRJ)

Carlos A. Montanari (IQSC/USP)

Denise F. S. Petri (IQ/USP)

Glaura G. Silva (UFMG)

Hélio F. dos Santos (UFJF)

Hugo Braibante (UFSM)

Marco T. Grassi (UFPR)

Maria Fernanda Pimentel (UFPE)

Paulo A. Porto (IQ/USP)

Paulo A. Z. Suarez (UnB)

Sergio A. S. Machado (IQSC/USP)

Silvio do D. Cunha (UFBA)

Telma L. G. Lemos (UFC)

Valdir Soldi (UFSC)

\section{SOCIEDADE BRASILEIRA DE QUÍMICA \\ Diretoria}

Presidente: Antonio Sálvio Mangrich (UFPR)

Vice-presidente: Vanderlan da Silva Bolzani (UNESP)

Secretário Geral: Norberto Peporine Lopes (USP/RP)

$1^{\circ}$ Secretário: Celso Camilo Moro (UFRGS)

Tesoureiro: Arnaldo Alves Cardoso (UNESP)

$1^{\circ}$ Tesoureiro: Luiz Henrique Catalani (USP)

Diretora Executiva: Dirce M. F. Campos

\section{Conselho Consultivo}

Cesar Zucco (UFSC)

Eliezer J. de L. Barreiro (UFRJ)

Jailson Bittencourt de Andrade (UFBA)

Luiz Carlos Dias (UNICAMP)

Paulo Cezar Vieira (UFSCar)

Solange Cadore (UNICAMP)

Editoração Eletrônica: Hermano - Tel.: (11) 5571-8937

Capa: Ana Paula Toscano - Tel.: (11) 9274-7523

Impressão: Copypress - Tel.: (11) 6215-5800
Copyright () 2007 Sociedade Brasileira de Química

Para publicação, requer-se que os manuscritos submetidos a esta revista não tenham sido publicados anteriormente e não sejam submetidos ou publicados simultaneamente em outro periódico. Ao submeter o manuscrito, os autores concordam que o copyright de seu artigo seja transferido à Sociedade Brasileira de Química (SBQ), se e quando o artigo for aceito para publicação.

O copyright abrange direitos exclusivos de reprodução e distribuição dos artigos, inclusive separatas, reproduções fotográficas, microfilmes ou quaisquer outras reproduções de natureza similar, inclusive traduções. Nenhuma parte desta publicação pode ser reproduzida, armazenada em bancos de dados ou transmitida sob qualquer forma ou meio, seja eletrônico, eletrostático, mecânico, por fotocopiagem, gravação, mídia magnética ou algum outro modo, sem permissão por escrito da detentora do copyright.

Embora todo esforço seja feito pela SBQ, Editores e Conselho Editorial para garantir que nenhum dado, opinião ou afirmativa errada ou enganosa apareçam nesta revista, deixa-se claro que o conteúdo dos artigos e propagandas aqui publicados são de responsabilidade, única e exclusiva, dos respectivos autores e anunciantes envolvidos. Conseqüentemente, a SBQ, o Conselho Editorial, os Editores e respectivos funcionários, diretores e agentes isentam-se, totalmente, de qualquer responsabilidade pelas consequiências de quaisquer tais dados, opiniões ou afirmativas erradas ou enganosas.

Photocopying information for users in the USA. The Item-Fee Code for this publication indicates that authorization to photocopy items for internal or personal use is granted by the copyright holder for libraries and other users registered with the Copyright Clearance Center (CCC) Transactional Reporting Service, provided the stated fee for copying beyond that permitted by Section 107 and 108 of the United States Copyright Law is paid. The appropriate remittance of $\$ 6,00$ per copy per article is paid directly to the Copyright Clearance Center Inc., 222 Rosewood Drive, Danvers, MA 01923, U.S.A.

Permission for other use. The copyright owner's consent does not extend to copying for general distribution, for promotion, for creating new works, or for resale. Specific written permission must be obtained from the Publisher for such copying.

The Item-Fee Code for this publication is 0100-4042\$6.00+ 0.00

Tiragem: 3700 exemplares

Circulação: Março/2007

Financiamento

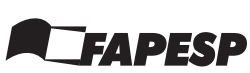

(versão on line)

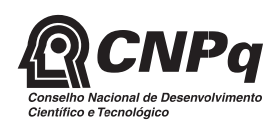

Pedido de assinatura e distribuição

Secretaria da SBQ

Instituto de Química - USP

Av. Prof. Lineu Prestes, 748

Bloco 3 - superior

Tel.: (011) 3032-2299/Fax: (011) 3814-3602

E-mail: sbqsp@iq.usp.br

Envio de manuscritos

Química Nova (Editoria)

Sociedade Brasileira de Química

C. Postal 26.037

05513-970 - São Paulo - SP - Brasil 